\title{
Brinquedo de Cura em terreiro de Mina
}

\author{
Mundicarmo Ferretti ${ }^{1}$
}

\section{Resumo}

A pajelança de negros, mais conhecida por Cura ou Pajé, é encontrada no Maranhão desde o século XIX entre a população negra. É encontrada atualmente em muitos terreiros da capital onde, interagindo com o Tambor de Mina (religião de matriz africana tradicional) e com a Umbanda (religião afro-brasileira difundida no Maranhão a partir da década de 1930), assume formas diversas. A Cura é muito procurada por pessoas que buscam a proteção de encantados e que acreditam no seu poder para desmanchar feitiços e curar diversas enfermidades. No Brinquedo de Cura - ritual público onde o pajé ou curador entra em transe com grande número de entidades espirituais -, o canto, realizado em português, estimula a participação da assistência batendo palma e, algumas vezes, tocando matraca ou dando alguns passos de dança. O repertório musical da Cura é muito rico e inclui cantigas transmitidas de geração em geração e outras que vão sendo "inspiradas" aos pajés ou que são "ensinadas pelos encantados" durante os rituais.

\section{Palavras-chave}

Cura/Pajelança, Tambor de Mina, Pajelança de negro, Brinquedo de Cura, Cantiga de pajé.

Recebido em 27 de junho de 2014

Aprovado em 18 de agosto de 2014

FERRETTI, Mundicarmo. Brinquedo de Cura em terreiro de Mina. Revista do Instituto de Estudos Brasileiros, Brasil, n. 59, p. 57-78, dez. 2014. D0I: http://dx.doi.org/10.11606/issn.2316-901X.v0i59p57-78

I Universidade Federal do Maranhão (UFMA, São Luís, MA, Brasil). 


\title{
Brinquedo de Cura in Terreiro de Mina
}

\author{
Mundicarmo Ferretti
}

\section{Abstract}

Black people's pajelança, commonly known as Cura (Curing) or Pajé, is found in Maranhão since the $19^{\text {th }}$ century among black population. It's currently found in many terreiros along the capital where, interacting with the Tambor de Mina (traditional religion with African roots) and Umbanda (African-brazilian religion defunded in Maranhão from the 1930s) takes several forms. Cura is very sought by people seeking for the protection provided by the encantados (enchanted) and who believe in its power to undo spells and heal several diseases. In Brinquedo de cura (pajelança dances) - the public ritual where the Pajé or curers goes in a trance with a wide variety of spiritual entities -, the singing, performed in Portuguese, stimulates the participation of the audience/participants by clapping and sometimes playing the matraca or dancing. Cure's music repertoire is very rich and includes songs passed along through generations and others "inspired" to the Pajés or "taught by the encantados" during the rituals.

Keywords

Cura/Pajelança, Tambor de Mina, Pajelança de negro, Brinquedo de cura, Pajé songs. 


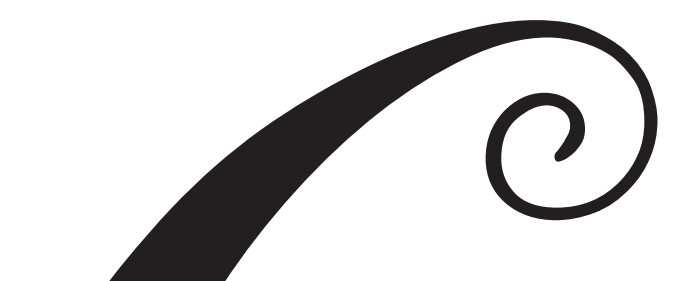

Brinca pajé, pajé não quer brincar Pega teu penacho e sacode o maracá ${ }^{2}$

antar e dançar é algo fundamental nos rituais públicos realizados em terreiros do Maranhão, quer no Tambor de Mina - religião tradicional de matriz africana ${ }^{5}$-, quer na Cura ou pajelança - manifestação religiosa e terapêutica apresentada como de origem indígena, mas encontrada entre a população negra do Estado antes mesmo do Tambor de Mina ganhar visibilidade em São Luís -, para a qual direcionamos nossa atenção especial nesse trabalho ${ }^{4}$. E, nesse contexto religioso, brincar é participar do ritual, quer como "mineiro", no Tambor de Mina, quer como pajé ou curador, na Cura - no Brinquedo de Cura ou ritual de Maracá.

A pajelança encontrada em muitos terreiros de religião afro-brasileira do Maranhão e do Pará, aqui também denominada pajelança de negro, não deve ser confundida com a pajelança cabocla da Amazônia, estudada por Eduardo Galvão e por Heraldo Maués ${ }^{5}$, como advertiu Vicente Sales ${ }^{6}$ e como temos tentado mostrar em nossos trabalhos, e nem deve ser identificada com o catimbó nordestino, pesquisado atualmente

2 Cantiga de Cura/Pajelança - Terreiro Fé em Deus (São Luís-MA).

3 FERRETTI, Mundicarmo. Desceu na guma: o caboclo do Tambor de Mina em um terreiro de São Luís. São Luís: EDUFMA, 2000.

4 FERRETTI, Mundicarmo. Pajelança e cultos afro-brasileiros em terreiros maranhenses. Revista Pós Ciências Sociais, São Luís, UFMA, v.8. n.16, p. 91-106, jul.-dez. 2011.

5 GALVÃO, Eduardo. Santos e visagens: um estudo da vida religiosa de Itá-Baixo Amazonas. 2. ed. São Paulo: Ed. Nacional; Brasília: INL, 1976. MAUÉS, R. Heraldo. $A$ ilha encantada: medicina e xamanismo numa comunidade de pescadores. Coleção Igarapé. Belém: EDUFPA, 1990.

6 SALES, Vicente. Cachaça, pena e maracá. Brasil Açucareiro, n.2, p.46-55, ago. 1969. 
por Luiz Assunção ${ }^{7}$, como parece sugerir Roger Bastide ${ }^{8}$, embora possa apresentar alguns elementos em comum com a pajelança cabocla e com o catimbó, principalmente no Pará ${ }^{\text {. }}$

A literatura antropológica sobre a pajelança de negro ou de terreiro de religião afro-brasileira é menos rica do que a existente sobre a pajelança cabocla e as informações disponíveis sobre a primeira são menos sistematizadas, mesmo quando se referem à do Pará, sobre a qual foram realizados os trabalhos acadêmicos mais antigos. Entre estes merecem destaque: o relatório de pesquisa da Missão Folclórica, organizada em São Paulo, por Mário de Andrade, realizada em Belém em 1938; as referências feitas por Vicente Sales, Napoleão Figueiredo e Anaiza Vergolino-Henry; os comentários de Roger Bastide; os trabalhos do casal Leacock e a pesquisa histórica de Aldrin Figueiredo ${ }^{10}$.

Entre os trabalhos mais antigos que tratam sobre a pajelança de terreiro maranhense merece destaque a tese de Costa Eduardo sobre o negro no Maranhão, publicada nos Estados Unidos. E, publicados bem mais recentemente, merecem destaque as pesquisas de Rosário Carvalho, os nossos trabalhos, baseados em pesquisa de campo realizada principalmente na capital maranhense, e um livro de Pai Euclides, babalorixá da Casa Fanti-Ashanti ${ }^{11}$.

7 ASSUNÇÃO, Luiz. Os Mestres da Jurema: Culto da Jurema em Terreiro de Umbanda no interior do Nordeste. In: PR ANDI, Reginaldo (Org.). Encantaria Brasileira: o livro dos Mestres, Caboclos e Encantados. Rio de Janeiro: Pallas, 2001. p. 182-215.

8 BASTIDE, Roger. O sagrado selvagem e outros ensaios. São Paulo: Companhia das Letras, 2006. p. 218.

9 Como mostrou Napoleão Figueiredo (FIGUEIREDO, Napoleão. Pajelança e catimbó na região bragantina. Rev. do Instituto Histórico e Geográfico de Alagoas, v.32, 1975/1976). A ligação com o catimbó parece clara quando se analisa o vocabulário da Cura e a letra de algumas músicas cantadas no Brinquedo de Cura e se encontra as palavras mesa, como sinônimo de ritual, mestre, como sinônimo de encantado ou de chefe e especialista do catimbó e quando se ouve cantos como: Abre mesa, abre mesa, abre mesa de ajucá (Terreiro Fé em Deus - São Luís-MA).

10 ALVARENGA, Oneyda. Babassuê: registros sonoros de folclore nacional brasileiro IV. São Paulo: Biblioteca Pública Municipal, 1950; SALES, Vicente. Cachaça, pena e maracá; FIGUEIREDO, Napoleão. Pajelança e catimbó na região bragantina; FIGUEIREDO, Napoleão e SILVA, Anaiza Vergolino e. Festa de santos e encantados, Belém: Academia Paraense de Letras. 1972; BASTIDE, Roger. O sagrado selvagem e outros ensaios. LEACOCK, Seth e LEACOCK, Ruth. Spitits of the Deep: a Study of an Afro-Brazilian Cult. New York: Anchor, 1975. FIGUEIREDO, Aldrin. A cidade dos encantados: pajelanças, feitiçarias e religiões afro-brasileiras na Amazônia. A constituição de um campo de estudo (1870-1950). 1996, Dissertação (Mestrado em História). Instituto de Filosofia e Cièncias Humanas, Universidade Estadual de Campinas - UNICAMP, 1996.

11 EDUARDO, Octávio da Costa. The Negro in Northern Brazil: A Study in Acculturation. New York: J.J. Augustin Publisher, 1948. SANTOS, Maria do Rosário Carvalho. 
Nos últimos anos, a literatura sobre pajelança de negro ou de terreiros do Maranhão e do Pará tem sido enriquecida com teses e dissertações de antropologia, como as de: Didier Laveleye, Gustavo Pacheco, Christiane Mota - sobre o Maranhão -, e de Gianno Quintas - sobre o Pará $^{12}$. Merece também destaque o vídeo produzido por Ana Stela Cunha sobre o quilombo de Damásio, no Maranhão ${ }^{13}$.

\section{Pajelança de terreiro no Maranhão e no Pará}

Os termos pajé e pajelança são amplamente utilizados para designar rituais e especialistas religiosos e terapêuticos ligados à cultura indígena, ou à cultura cabocla, geralmente rural, encontrados principalmente no Norte do Brasil. Mas no Maranhão, desde meados do século XIX, são também muito utilizados para designar rituais e especialistas religiosos negros (africanos e afro-descendentes) destinados à "cura de feitiço" ou para "dar passagem" a entidades espirituais como Rei Sebastião, princesas, caboclos e outras, algumas vezes encantadas em animais (pássaros, peixes, répteis e mamíferos). No contexto maranhense,

Boboromina, Terreiros de São Luís: uma interpretação sócio-cultural. São Luís: SECMA/SIOGE, 1989. FERRETTI, Mundicarmo. Tambor de Mina, Cura e Baião na Casa Fanti-Ashanti. Documento sonoro/LP e folheto explicativo. São Luís: SECMA, $1^{\circ}$ Plano Fonográfico. 1991; FERRETTI, Mundicarmo (org.). Pajelança do Maranhão no século XIX: o processo de Amélia Rosa. São Luís: CMF/Fapema, 2004. FERRETTI, Mundicarmo. Pajelança e cultos afro brasileiros em terreiros maranhenses. FERREIR A, Euclides. Pajelança. São Luís: Ed. do Autor, 2003.

12 LAVELEYE, Didier de. Peuple de la mongrove: approche ethnologique d'un espace social métissé (région de Cururupu-Mirinzal, Maranhão, Brésil). 2001/2002. Tese (Doutorado em Cièncias Sociais - Antropologia). Université Libre de Bruxelles - Faculté de Sciences Sociales, Politiques et Économique. Année Academique 2001/2002. PACHECO, Gustavo. Brinquedo de Cura: um estudo sobre a pajelança maranhense. 2004. 283 f. Tese (Doutorado em Antropologia). Museu Nacional Universidade Federal do Rio de Janeiro, 2004. MOTA, Christiane de Fátima. Pajés, Curadores e Encantados: pajelança na baixada maranhense. São Luís: EDUFMA, 2009. QUINTAS, Gianno. Entre maracás e tambores: pajelança nas religiões afro-brasileiras. 2007. 265 f. Dissertação (Mestrado em Antropologia), Universidade Federal do Pará, 2007. MAUÉS, Heraldo e VILLACORTA, Gisela, em um trabalho sobre pajelança cabocla amazônica, realizaram um levantamento mais completo sobre pesquisas desenvolvidas no Pará (ver PRANDI, op. cit.). Sobre a pajelança cabocla do Pará, merece também destaque o livro da pajé Zeneida Lima (LIMA, Zeneida. O mundo dos caruanas e a revolta de sua ave. 4 ed. Belém: CEJUP, 1998).

13 CUNHA, Ana Stela. Falando em quilombo: a implantação da Lei 10639 na sala de aula. (Video). Damasio (MA), Jan/2005. 
embora se costume relacionar a Cura (pajelança de negro ou de terreiro) à cultura indígena, ela se aproxima mais do Tambor de Mina, reconhecido como de matriz africana, como temos procurado demonstrar.

Há quem afirme que a pajelança de terreiro do Pará é mais próxima de modelo indígena e da pajelança encontrada em 1948 por Eduardo Galvão em Gurupá (PA), em comunidade do Baixo Amazonas - por ele descrita em Santos e Visagens ${ }^{14}$-, do que da pajelança do Maranhão, sobre a qual temos direcionado nossa atenção nos últimos anos. Infelizmente não dispomos de informações que nos permitam fazer uma avaliação mais aprofundada das semelhanças e diferenças existentes entre elas. Os dados da pesquisa realizada pela Missão Folclórica em Belém, no terreiro de Satiro, são mais completos sobre o Babassuê ou Brinquedo de Santa Bárbara (que corresponde a uma mina de caboclo) do que sobre a pajelança realizada por Satiro. Em 1938, quando os pesquisadores paulistas estiveram em São Luís e em Belém registrando "musicas de folclore", os terreiros precisavam solicitar licença à polícia para realizar 'toques' de mina e ninguém ousava solicitar licença para realizar rituais de Cura, pois a pajelança era proibida. Isso explica por que as músicas de pajelança, gravadas em Belém naquela oportunidade, tenham sido cantadas por Satiro no hotel em que estavam hospedados aqueles pesquisadores e não durante a realização de um ritual, como as do Babassuêt ${ }^{15}$.

Contudo, ao que tudo indica, a pajelança de Satiro parece mais próxima da pajelança maranhense que temos pesquisado nos últimos anos do que da paraense descrita por Eduardo Galvão ${ }^{16}$.

De acordo com o relatório de pesquisa da Missão Folclórica, Satiro era natural do Pará, não conhecia o Maranhão - só teria viajado para Manaus - e teria aprendido o Babassuê com seus pais (segundo ele, um jeje e outro nagô). Essas informações divergem das transmitidas por fontes maranhenses que afirmam que Satiro e seu irmão Pedro eram filhosde-santo de Mãe Anástacia, fundadora do Terreiro da Turquia (de São Luís) e irmã-de-santo de Mãe Doca - maranhense de Codó, considerada a introdutora da mina no Pará ${ }^{17}$-, e que Satiro teria estado em São Luís

14. GALVÃO, Eduardo. Santos e visagens.

15 ALVARENGa, Oneyda. Babassuê.

16 O relatório da Missão Folclórica, publicado em 1950 (ALVARENGA, Oneyda. Babassuê), não deve ter sido analisado por Eduardo Galvão, daí porque não aparece na bibliografia de Santos e Visagens (op. cit.), como a obra de Octávio da Costa Eduardo sobre a aculturação do negro no Maranhão (The Negro in NorthernBrazil).

17 FERREIRA, Euclides. Album Fotográfico. Arquivo de um Babalorixá. São Luís: Ed. do Autor, 2004. p. 89. 
pelo menos uma vez, no ano de 1917, quando foi fotografado participando de um ritual naquele terreiro ${ }^{18}$. Embora não deva ter sido preparado na "linha de tauari" (de Cura/pajelança) no terreiro da Turquia, inclusive porque não se realizava Cura/pajelança naquele terreiro, pode ter sido influenciado pela pajelança de terreiro do Maranhão. É bom lembrar que tanto Mãe Anastácia como Mãe Doca foram iniciadas em São Luís, por Manoel Teu Santo, pai-de-santo que, entre 1895 e 1899, apareceu várias vezes em jornais maranhenses como pajé ${ }^{19}$, embora tenha sido apresentado por Pai Euclides como africano ou nigeriano ${ }^{20}$.

A "linha de tauari", referida por Satiro em entrevista aos pesquisadores paulistas da Missão Folclórica, tal como a denominada "linha de pena e maracá" e a "linha de Cura", referida em outros terreiros, remete à pajelança de negro (realizada em terreiro de religião afro-brasileira). A denominação tauari decorre do uso de um cigarro fumado pelo pajé durante os rituais - geralmente longo e enrolado em fibra têxtil retirada de árvore de mesmo nome. Como o penacho e o maracá, o tauari não é usado na Mina tradicional e simboliza a pajelança, tal como as glanchamas - faixas artesanais, fitas ou cordões que são amarradas em várias partes do corpo dos pajés "para a sua firmeza e proteção" durante os rituais ${ }^{21}$.

\section{Cura ou Pajelança em terreiros afro-brasileiros do Maranhão}

Apesar de a Casa das Minas e a Casa de Nagô - os terreiros de mina mais antigos - não realizarem rituais de pajelança, esses rituais são encontrados atualmente em muitos terreiros da capital maranhense e já eram oficiados no final do século XIX em pelo menos um terreiro de Mina de São Luís - o do Justino, oriundo da Casa de Nagô -, como registrado em jornal de circulação em São Luís ${ }^{22}$.

18 FERREIRA, Pajelança, p. $5^{2}$.

19 SANTOS, Thiago Lima dos. Navegando em duas águas: Tambor de Mina e Pajelança em São Luís do Maranhão na virada do século XIX para o XX. 2014. $198 \mathrm{f}$. Dissertação (Mestrado em Ciências Sociais), Universidade Federal do Maranhão, 2014 .

20 FERREIR A, Euclides. Itans de dois terreiros nagô. São Luís: Ed. do Autor, 20o8. p. 67.

21 FERREIRA, Pajelança, p. 76.

22 SANTOS, Thiago Lima dos. Navegando em duas águas, p. 132. 
Em meados do século XIX, a pajelança era uma prática muito recorrente no Maranhão. Além de a medicina ser então ainda pouco desenvolvida e difundida, os pajés conheciam "remédios caseiros" e eram também muito procurados pela população para desmanchar "malefícios" e curar doenças que se acreditava terem sido provocadas por feitiços, feitos por desafetos ou encomendados a pessoas conhecidas como feiticeiras. Com a organização dos serviços médicos, a pajelança passou a ser muito combatida, mas continuou a ser procurada pela população.

Atuando na área de saúde e atraindo muitos frequentadores para as suas festas e rituais públicos, os pajés enfrentaram severa perseguição policial, mesmo quando realizavam seus rituais na periferia da cidade, para onde muitos se transferiram ou onde se estabeleceram, e foram objeto de muitos comentários preconceituosos de jornalistas.

Tudo indica que a primeira pajé negra a ter seu nome amplamente divulgado em jornais de São Luís tenha sido Amélia Rosa - negra alforriada cognominada "rainha da pajelança", processada em 1876 e condenada a 10 anos de prisão ${ }^{23}$. Mas sabe-se que, antes do processo de Amélia Rosa, a pajelança já era realizada no Maranhão por negros, inclusive por escravos ${ }^{24}$, como pode ser constatado na análise de Posturas das vilas de Codó e de Guimarães transcritas a seguir:

Lei $n^{0} 241$ - 13 de setembros de 1848 (Postura da villa de Codó). Art. 22. Toda e qualquer pessoa que se proposer a curar feitiços, sendo livre pagará multa de vinte mil reis, e soffrerá oito dias de prisão, e sendo escravo haverá somente lugar a multa que será paga pelo senhor do dito escravo.

Lei $n^{0} 400$ - 26 de agosto de 1858 (Postura da villa de Guimarães). Art. 31. Os que curão de feitiço (a que o vulgo dá o titulo de pagés) incorrerão na pena de cinco mil reis, e na falta de meios ou reincidência, de 10 a 20 dias de prisão.

Mas, no final do século XIX, os pajés possuíam um perfil comparável ao de pais e mães de terreiros de mina abertos por afro-descendentes, que se tornaram visíveis mais tarde na capital maranhense, onde se

23 FERRETTI, Mundicarmo. Pajelança do Maranhão.

24. Thiago Lima dos Santos (Navegando em duas águas, p.1ol) cita um levantamento de casas habitadas por escravos em São Luís, realizado pela Guarda Municipal, em 1835, onde se faz referência a duas mulheres que tinham como atividade declarada a cura de feitiçaria, que mais tarde foi denominada quase exclusivamente pajé. 
cultua e entra em transe principalmente com entidades não africanas nobres, como Rei Sebastião, e caboclas (populações rurais tradicionais). Embora Amélia Rosa tenha sido processada por sevícias em uma escrava que declarou tê-la procurado por problemas de saúde, no ano anterior, fora presa por realizar rituais em sua casa, com a participação de várias pessoas iniciadas por ela numa nova religião - "Pajé" (pajelança) - que realizava várias festas de santos e onde se recebia Rei Sebastião ${ }^{25}$.

De acordo com a tradição oral, a realização de rituais de Mina e de Cura/pajelança pelas mesmas pessoas ou no mesmo terreiro, embora já ocorrida no século XIX, tornou-se mais frequente na década de 1930 , quando foi adotada por vários curadores para fugir à perseguição policial que era direcionada especialmente aos pajés. Contudo Pai Euclides, em seu livro sobre pajelança ${ }^{26}$, faz referência a 38 curadores de São Luís que não dançavam Mina, conhecidos por ele em sua infância (década de 1940). Pai Euclides cita também, na mesma obra, 24 mineiros que dançavam Cura, incluindo-se entre eles ${ }^{27}$.

Nossas observações sobre o "Brinquedo de Cura” - ritual público da pajelança maranhense - foram iniciadas em 1982, na Casa Fanti-Ashanti, e se estenderam a diversos terreiros e a casas de curadores da capital maranhense e de outros municípios da Ilha de São Luís ${ }^{28}$. Observamos também em Cururupu (MA), na casa do curador Betinho, um ritual de tambor com toque de maracá e atendimento a clientes, o que ocorre raramente em rituais realizados em terreiros de São Luís.

Em São Luís, as ligações de pajés com o Tambor de Mina e de mineiros com a Cura/pajelança são normais, mas possuem formas e graus variados ${ }^{29}$. Mas, como tanto os curadores ou pajés como os mineiros

25 FERRETTI, Mundicarmo. Pajelança do Maranhão.

26 FERREIRA, Euclides. Pajelança. p. 51.

27 Em alguns terreiros de São Luís, a linha de mina era de responsabilidade de uma pessoa e a de cura, de outra, como ocorreu no de Mãe Denira, onde a linha de cura era comandada por seu marido (por Biná).

28 Tivemos oportunidade de observar muitos rituais públicos de pajelança realizados em São Luís por Dona Clarinda, no bairro de Santo Antônio; Seu Adelmo, na Vila Palmeira; Dona Filomena e Mãe Raimundinha, no João Paulo; Dona Santana e Waldir, no Maracanã; Mãe Yolanda, no terreiro de José João, no Anjo da Guarda; por Pai Airton, na Liberdade; Dona Zizi, no Lira; Joãozinho, na Vila Nova; Pai Osvaldo e Mãe Elzita, no Sacavém. Assistimos também a rituais públicos de Cura em outros municípios da ilha de São Luís: no terreiro de Aroldinho, em Ribamar; e os de Itaparandi e de Itabajara, em Passo do Lumiar.

29 No nível mais baixo, poderia ser citado o de Dona Filomena, tia de Mãe Elzita, que tivemos a oportunidade de conhecer em São Luís, que, embora sem ser considerada mineira, realizava rituais de Cura em sua residência e participava de alguns rituais de mina no terreiro de sua sobrinha. 
maranhenses são, em sua maioria, afro-descendentes e uns participam dos rituais dos outros, é de se esperar que as diferenças maiores entre os rituais de Cura só apareçam mais claramente quando se compara o Brinquedo de Cura de São Luís com o tambor de curador realizado fora da capital maranhense, como o de Cururupu, ou com a pajelança de terreiros paraenses - esta possivelmente realizada por uma população mais cabocla ou menos negra do que a da capital maranhense.

Embora a pajelança seja apresentada em São Luís (MA) como "linha de água doce", e embora os encantados da "linha de Cura"/Pajelança sejam classificados genericamente como "mãe d'água" e, em Belém (PA), como "povo d'agua", "companheiro ou bicho do fundo", o pajé pode ser também apresentado como “ave de encantado", pois, à semelhança do que ocorre com médiuns (filhos de santo) em terreiros de Mina de caboclo e de Umbanda, onde são frequentemente apresentados como "cavalos" das entidades espirituais (africanas e não africanas), acredita-se que possibilitam a movimentação dos encantados para os mais diversos lugares ${ }^{30}$. Mas é possível que essa associação do pajé, do "mineiro" e do umbandista a animais (ave e cavalo) seja apenas mais uma forma encontrada pela população afro-brasileira para marcar a diferença entre a Mina e Cura/pajelança nos terreiros do Maranhão e do Pará, já sinalizada pela classificação da Mina como "linha de água salgada" e Cura/pajelança como "linha de água doce". 31

A identificação do pajé com uma ave poderia também apontar para algumas de suas características especiais. Como as aves (animais), representadas geralmente na Cura, como canoras e livres para voar, os pajés cantam e recebem encantados que "passam" em muitos terreiros e que são conhecidos em muitos lugares.

Sou arara cantadeira, arara

Rainha das curadeiras, arara

Gavião, gavião, ô meu gavião real,

Eu peço as asas gavião, q'eu também quero voar ${ }^{32}$

30 Essa identificação com "ave" é mais conhecida no Pará (ver: LIMA, Zeneida. $O$ mundo místico dos caruana e a revolta de sua ave. $4^{\mathrm{a}}$ ed. Belém: CEJUP, $1998 ; \mathrm{1}^{\mathrm{a}}$ ed. de 1991), mas pode ser também encontrada no Maranhão (ver: FERREIRA, Euclides. Pajelança, p.ı).

31 E, nesse caso, a associação a animais teria uma função comparável à encontrada por Lévy-Strauss no sistema de classificação australiano (LÉVY-STRAUSS, Claude. Totemismo Hoje. Petrópolis: Vozes, 1975).

$3^{2}$ Brinquedo de Cura de Raimunda Viegas (São Luís - MA). 


\section{Brinquedo de Cura em terreiros de Mina do Maranhão}

Talvez por ser mais envolvida com atividades terapêuticas do que o Tambor de Mina, a pajelança encontrada em terreiros de São Luís é mais conhecida como "Cura", e os rituais públicos realizados por pajés ou curadores, naqueles terreiros, são denominados "Brinquedos de Cura" (embora também sejam conhecidos como "pena e maracá" - em alusão ao uso ritual pelo pajé de um penacho, geralmente de arara, e do maracá, tocado por ele durante as cerimônias $)^{33}$.

Nos terreiros de São Luís, o "Brinquedo de Cura" é realizado poucas vezes por ano, mas atrai grande número de pessoas. Ao contrário do que ocorre nos toques de Mina, nele o pajé (ou "pajoa") "brinca" geralmente sozinho no salão, ou brinca (canta e dança) durante um certo tempo (pelo menos por hora e meia), dando passagem a grande número de entidades - no que também difere do que ocorre no Tambor de Mina -, cada uma delas cantando um certo número de músicas, passando depois o comando do ritual para outros que já se encontram no salão e que vão se sucedendo, mas cada um atuando por um tempo sempre menor do que o transcorrido com o primeiro, que organizou o ritual.

Nos rituais públicos denominados "Brinquedo de Cura", o pajé é a figura central e não apenas puxa o canto, mas também canta durante toda a sua realização - embora costume ser acompanhado por pessoas do seu grupo (tocando pandeiro, cabaça e, às vezes, tambor e/ou matraca) e também por pessoas da assistência (batendo palma e cantando). Como geralmente inicia os trabalhos já em transe, o seu canto e toda a sua performance é atribuída aos encantados que "passam por sua cabeça" durante a realização do ritual. Algumas das entidades recebidas, ao se anunciarem pelo canto, são cumprimentadas por várias pessoas. Outras, depois de se apresentarem, cumprimentam alguns dos presentes ou toda a assistência. As pessoas mais conhecidas costumam ser cumprimentadas várias vezes pelo pajé, cada vez por uma entidade diferente.

No ritual de Cura (pajelança de terreiro), o canto, que é realizado em português, costuma ser acompanhado pela assistência batendo palma e, às vezes, dançando quase sem sair do lugar, o que confere ao ritual uma atmosfera alegre e contagiante, diferente da observada nos rituais de Mina realizados no mesmo terreiro. Mas, como as entidades

33 De acordo com Pai Euclides, o maracá é usado pelo mestre de cura para captar a energia espiritual e tem um som semelhante ao do chocalho da cobra cascavel; já o penacho é usado por ele como adereço nos rituais e nos trabalhos de cura para espanar as enfermidades dos clientes (FERREIRA, Euclides. Pajelança, 2ooz). 
recebidas pelos pajés são muito diferentes umas das outras, a atmosfera do ritual vai se modificando, acompanhando o estilo das entidades recebidas por ele. A animação maior acontece geralmente quando são recebidas suas entidades mais importantes ou as que possuem uma clientela maior - encantados conhecidos como 'bons curadores'.

No "Brinquedo de Cura", o pajé entra em transe (“da passagem") com grande número de encantados de diversas categorias (nobres, caboclos, velhos, crianças, sereias, surrupiras, cobras, aves, peixes e outras) que se acredita terem desaparecido da Terra e se tornado invisíveis, mas não são considerados espíritos de mortos. Contudo, só algumas das entidades recebidas pelos pajés demoram mais tempo: cantando, abraçando e abençoando os membros do terreiro, e cumprimentando amigos e clientes. As mais conhecidas como curadoras podem se dirigir a algumas pessoas em particular para benzer ou receitar algum medicamento, o que raramente é observado quando o Brinquedo é realizado em terreiros que se definem como de Mina, mas costuma ocorrer frequentemente, quando o pajé é mais conhecido como 'curador' do que como 'mineiro'. No 'Brinquedo de Cura' realizado em São Luís, esses atendimentos, quando ocorrem, são realizados geralmente fora do salão, em lugar reservado, enquanto o ritual público prossegue sob o comando de outro pajé ou é assumido por seus discípulos.

Além de conhecer bem os cantos de abertura e de encerramento do "Brinquedo de Cura", o pajé precisa dominar o grande repertório musical da Cura e ter conhecimento seguro da classificação das entidades espirituais, pois durante o ritual não pode repetir música já cantada e nem misturar as "linhas" ou categorias de encantados.

Tudo indica que essa importância do canto na pajelança de negro já era conhecida no último quartel do século XIX, já que, no processo de Amélia Rosa, foi indagado a pessoas que a conheciam se ela cantava quando atuava como pajé. É possível que algumas das músicas do repertório de Amélia Rosa tenham passado de geração em geração e sejam repetidas ainda hoje em rituais de Mina ou de Cura/pajelança realizados em terreiros maranhenses, pois uma das entidades espirituais recebidas no seu grupo era o Rei Sebastião, encantado conhecido atualmente como chefe da encantaria dos Lençóis maranhenses, sincretizado no Maranhão com Xapanã - divindade africana associada a São Lazaro, santo também cultuado por Amélia Rosa ${ }^{34}$.

34. Ver gravação em áudio e em vídeo realizada por Roberto Machado (MACHADO, Roberto. A lenda do Rei Sebastião. 1979. Vídeo Documentário e CD. 1979). 
Rei Sebastião é guerreiro militar

Ô Xapanã, ele é pai de terreiro

Ele é guerreiro na guma imperiá

Quem tiver sua vista boa

À meia-noite saia e venha ver

Rei Sebastião carregado de corrente

Fazendo a terra tremer ${ }^{35}$

O que se canta no "Brinquedo de Cura" depende das entidades recebidas pelo pajé, mas existem músicas que são cantadas por muitos, músicas cantadas por poucos e músicas que são "tiradas" pelo pajé durante um "Brinquedo de Cura" e que depois são incorporadas ao repertório de Cura da casa ou de um determinado pajé. No último caso, são ensinadas à assistência durante o ritual ou guardadas na memória por alguma pessoa da casa e depois suas letras são registradas em um caderno, para que não sejam esquecidas.

As músicas de Cura raramente fazem referência a entidades africanas, como ocorreu na doutrina de Rei Sebastião citada anteriormente, mesmo quando o "Brinquedo de Cura" é realizado em terreiro que se define como Mina (de religião afro-brasileira). Já as referências a santos e a rezas católicas são muito frequentes, principalmente na abertura e no encerramento do ritual.

Lá vai eu, gente, lá vai eu

Com a minha chave de ouro

Quem me deu foi Nossa Senhora

Eu vou abrir o meu tesouro

Lá vai eu, gente, lá vai eu

Com a minha chave na mão

Quem me deu foi São Miguel

Eu vou abrir o meu salão

Abre mesa, abre mesa

Abre mesa de "Juncá"

Trouxe linha, lá vem linha

Trago linha pra curar. ${ }^{36}$

35 Cantiga de Cura da casa de Memê - Guimarães (MA).

${ }_{3} 6$ Canto de abertura de Cura no Terreiro Fé em Deus. AIRES, Maria do Socorro. Terreiro Fé em Deus: um estudo de rituais não africanos. 2008, 80 f. Monografia (Ciências Sociais), UFMA. 2008, p. 57 . 
A dança do pajé depende da categoria da entidade por ele recebida, mas também de formas especiais como elas são representadas. Assim, embora os nobres costumem ser mais reservados e solenes, Antonio Luís, “o Corre Beirada", filho de Dom Luiz Rei de França, conhecido como bom curador, é frequentemente recebido como farrista e pode chegar cambaleando, como se estivesse embriagado; Joaozinho de Légua costuma ser recebido como uma criança brincalhona e travessa; a princesa Doralice, filha do Rei da Bandeira, como uma menina meiga e delicada; e Jurema, como uma índia flecheira.

Quem quiser saber meu nome

Bate palma que eu quero ver (...)

Eu não quero água, eu não quero água

Eu não quero água,

Eu não saio daqui sem beber $^{37}$

Como o pajé entra em transe também com pessoas tidas como encantadas em animais (ou com animais), a coreografia do "Brinquedo de Cura" realizado em terreiros maranhenses é bastante variada, pois na dança ele aponta para características daqueles animais (voar, rastejar, mergulhar, pular etc.).

Chegou dona Rosalina

Cobra grande da lagoa ${ }^{38}$

A Rã Preta é dourada

Mas eu moro é no banzeiro

Do Olho d’Água ${ }^{39}$

Essa identificação com animais é também muito encontrada na Mina-jeje onde, por exemplo, se diz que o vodum Bossucó se transforma em cobra, Alogue, em sapo, e Abê, numa pescada. Vários voduns da Mina-jeje fazem também uso do fumo, que é muito utilizado por encantados na Cura, mas enquanto os primeiros fumam cachimbos de cabo longo, fora do barracão e, geralmente, depois do ritual, as entidades da Cura costumam fumar durante o ritual cigarros de tauari, charutos

37 Cantiga do encantado Corre-Beirada - Cura - Terreiro Fé em Deus (São Luís - MA).

38 Cura do terreiro de Umbanda Luz e Caridade (São Luís - MA).

39 Cura na Casa de Raimunda Viegas (São Luís - MA). 
preparados com fumo de rolo, cachimbos, e também charutos e cigarros industrializados.

Na Cura, o pajé incorporado costuma tomar chá e às vezes ingerir, fora do salão, outras bebidas (cachaça, cerveja etc.), tal como também ocorre em algumas casas nos transes de caboclos no Tambor da Mina diferentemente dos voduns jeje-nagô, alguns caboclos no Tambor da Mina fazem uso de bebidas alcoólicas. Mas a ingestão de bebida alcoólica no barracão ou durante o ritual é muito criticada, embora esta seja considerada normal nos transes com encantados do Terecô (outra denominação religiosa de matriz africana do Maranhão), ou da "linha da mata de Codó”, comandada por Legua Bogi Buá, classificado por uns como caboclo e por outros, como vodum cambinda.

\section{Considerações finais}

Muito mais se tem a pesquisar e a dizer sobre a Cura ou pajelança em terreiros de religião afro-brasileira. Como procuramos mostrar aqui, a Cura e o seu ritual público denominado Brinquedo de Cura é um aspecto da cultura popular maranhense tradicional que tem uma identidade forte, apesar do sincretismo claro com o catolicismo, com a Mina, com a pajelança cabocla, com o catimbó e com outros aspectos da religiosidade popular. As perseguições aos curadores ocorridas no passado, a expansão da Umbanda e a tendência atual de enaltecimento da cultura africana têm levado muitos curadores a assumir outra identidade e a deixar de se apresentar como pajé ou curador e a se declarar mineiro, umbandista, espírita ou espiritualista, mas esse processo não implica abandono de crenças e de práticas tradicionais ligadas à Cura.

O Brinquedo de Cura pode ser organizado em qualquer lugar, utilizando-se pandeiro e/ou maracá ou até mesmo apenas batidas de palma, não havendo exigência de obrigações (oferendas etc.) elaboradas e dispendiosas para chamar os encantados, o que tem facilitado sua proliferação ao longo dos anos.

Nos terreiros onde se realizam rituais de Mina e de Cura, a Cura e a Mina se harmonizam muito bem, uma vez que, além de dirigidos e participados pelas mesmas pessoas, vários encantados participam das duas - "navegam nas duas águas", salgada (Mina) e doce (Cura). Essa integração é declarada em letras de músicas cantadas em rituais, como a apresentada a seguir: 
Eu nasci nas águas doces,

Na salgada me criei

Nessas águas brasileiras

Todas elas já andei.

Eu nasci nas águas doces,

Na salgada me criei

Eu sô uma cobra, Juruna,

Lá nas matas me encantei. ${ }^{40}$

Mas existem conflitos entre elas. A Cura se opõe a todo trabalho classificado como feitiço ou magia negra, frequentemente atribuído a exus e espíritos pouco evoluídos, de "linha de esquerda", e à ação de "macumbeiros" e quimbandeiros (afro-brasileiros), como declarado na letra de uma das músicas cantadas no Terreiro Fé em Deus (São Luís-MA):

Aê macumbeiro, o que tu faz com a mão

Eu desmancho com o pé (...).

No Brinquedo de Cura, embora as músicas e outros elementos mais tradicionais sejam apresentados na abertura e no encerramento dos rituais, às vezes, o repertório mais tradicional só é cantado depois de várias horas de "trabalho", quando a maioria das pessoas da "assistência" já foi embora.

O repertório musical da Cura é muito rico e, como as letras das músicas são em português, a participação da assistência é maior, cantando e batendo palma. Algumas músicas são passadas de geração em geração e cantadas em vários terreiros com pequena variação. Outras são "tiradas" pelos encantados durante os rituais ou "dadas" por eles aos pajés em sonho ou em vigília e ensinadas por eles durante os rituais ${ }^{41}$.

40 A primeira versão recolhida em ritual da Casa Fanti-Ashanti, e a segunda, na Cura de Raimunda Viegas (São Luís-MA).

41 No período de 1984 a 1987 realizando, com apoio da FUNARTE, pesquisa na Casa Fanti-Ashanti, recolhemos cerca de 500 músicas em rituais de Cura e 500 músicas cantadas em português nos rituais de Mina observados daquele terreiro. Algumas dessas músicas foram inseridas no disco Tambor de Mina, Cura e Baião, produzido em 1991 pela então Secretaria de Cultura do Estado do Maranhão (SECMA), atualmente disponível em www.museuafro.ufma.br. Considerando que a Cura era realizada na Casa só uma vez por ano e que os toques de Mina ocorriam várias vezes no ano, pode se ter uma ideia da riqueza daquele repertório. 
Alguns rituais de Cura e algumas músicas cantadas durante sua realização conferem à Cura uma atmosfera parecida com a encontrada em brincadeiras de Bumba-meu-boi do Maranhão, principalmente quando são acompanhadas de matracas, como ocorre no Terreiro Fé em Deus, de Mãe Elzita, no bairro do Sacavém. No Maranhão, os encantados costumam participar e solicitar a realização de brincadeiras folclóricas, como Bumba-meu-boi, Tambor de Crioula, e da festa do Divino Espírito Santo. Essa prática é encontrada não só ligada a entidades espirituais não africanas (caboclos, pretos velhos), mas também a entidades da Mina jeje-nagô, como o vodum Averequete, que "adora" São Benedito e gosta de Tambor de Crioula.

A comparação do Brinquedo de Cura realizado em diversos terreiros de Mina e de Umbanda de São Luís mostra que aquele ritual, apesar de se apresentar de modo diferente, possui uma estrutura semelhante. Normalmente o pajé ou “pajoa” entra no salão já em transe, acompanhado de um ajudante, cantando uma música de abertura e sacodindo um maracá. No salão, se dirige ao altar ou a uma mesa preparada para a Cura, onde não podem faltar imagens de santos, velas, cigarros, bebidas e uma cadeira onde, não raramente, se colocam algumas "panas" (ou painas) - lenços de seda de várias cores, pertencentes aos chefes de suas principais correntes de encantados, trazidos por eles na mão durante o Brinquedo.

$\mathrm{Na}$ abertura do ritual geralmente se invoca algum santo e, frequentemente, Nossa Senhora da Conceição, conhecida como patrona da "linha de água doce"/Cura, e se canta "abrindo a mesa", para iniciar a passagem das entidades espirituais, como declarado nas letras das músicas de abertura da Cura da Casa Fanti-Ashanti, gravadas no disco Tambor de Mina, Cura e Baião ${ }^{42}$ :

Nossa Senhora da Conceição

Ora queira me valer, ó Mãe Senhora

Nessa ocasião

Laurindo, tu abre a mesa

Ô abre essa mesa reá

Com Deus e Nossa Senhora

Meu São José de Ribamar

4, FERRETTI, Mundicarmo. Tambor de Mina, Cura e Baião na Casa Fanti-Ashanti/ $M A$. (disponível em www.museuafro.ufma.br). 
Marajá, Marajá Tendá (bis)

Bota rama no caminho

Não deixa contrário entrar

No encerramento da Cura são cantadas músicas de despedida, anunciando o retorno dos encantados para as matas, para as ondas do mar ou para um rio, e músicas falando novamente em santos de devoção e em Nossa Senhora ${ }^{43}$ :

Nossa Senhora do Carmo,

Minha Virgem das Mercês

Eu vou fechar o meu trabalho

Nossa Senhora vem ver

Me desamarrem meus companheiros,

Eu vou embora para o rio Madeira

\section{Sobre a autora}

\section{Mundicarmo Maria Rocha Ferretti}

Professora do Programa de Pós-Graduação em Ciências Sociais da Universidade Federal do Maranhão (UFMA, São Luís, MA, Brasil). Professora emérita da Universidade Estadual do Maranhão (UEMA). Doutora em Ciências Sociais/Antropologia pela Universidade de São Paulo (USP). Pesquisadora de Antropologia das populações afro-brasileiras. E-mail: mundicarmorf@gmail.com

43 Idem, ibidem. 


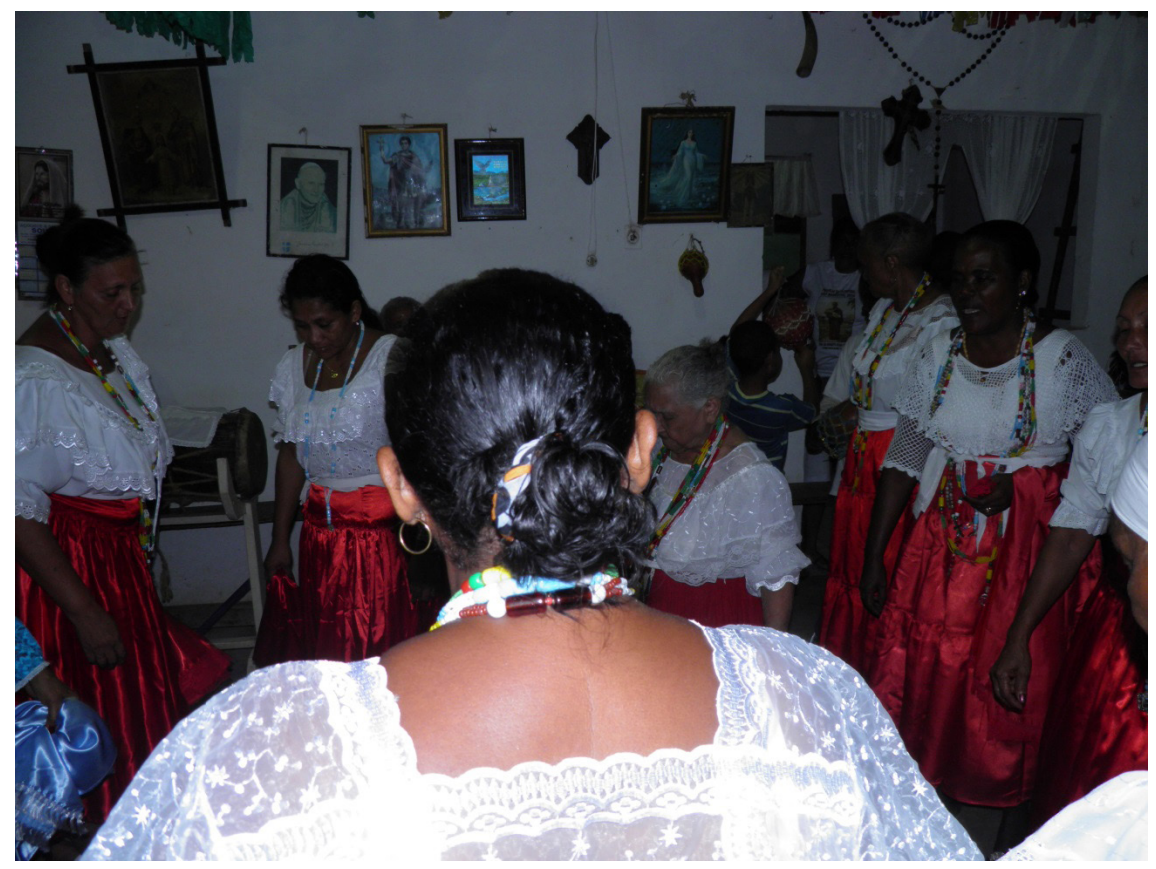

Figura 1: Tambor de Mina no terreiro do Justino - Vila Embratel - São Luís (MA) - 2001. Foto de Sergio Ferretti.

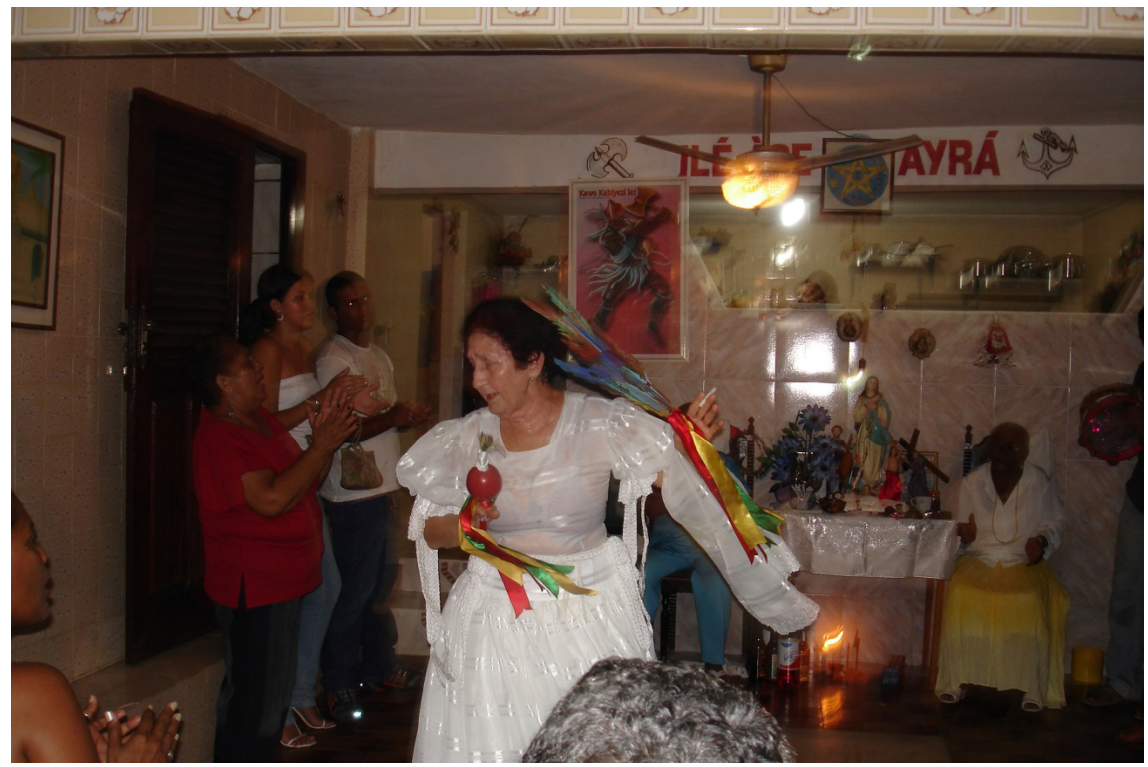

Figura 2: Brinquedo de Cura - Raimunda Viegas - São Luís (MA) - 2007. Foto de Mundicarmo Ferretti. 


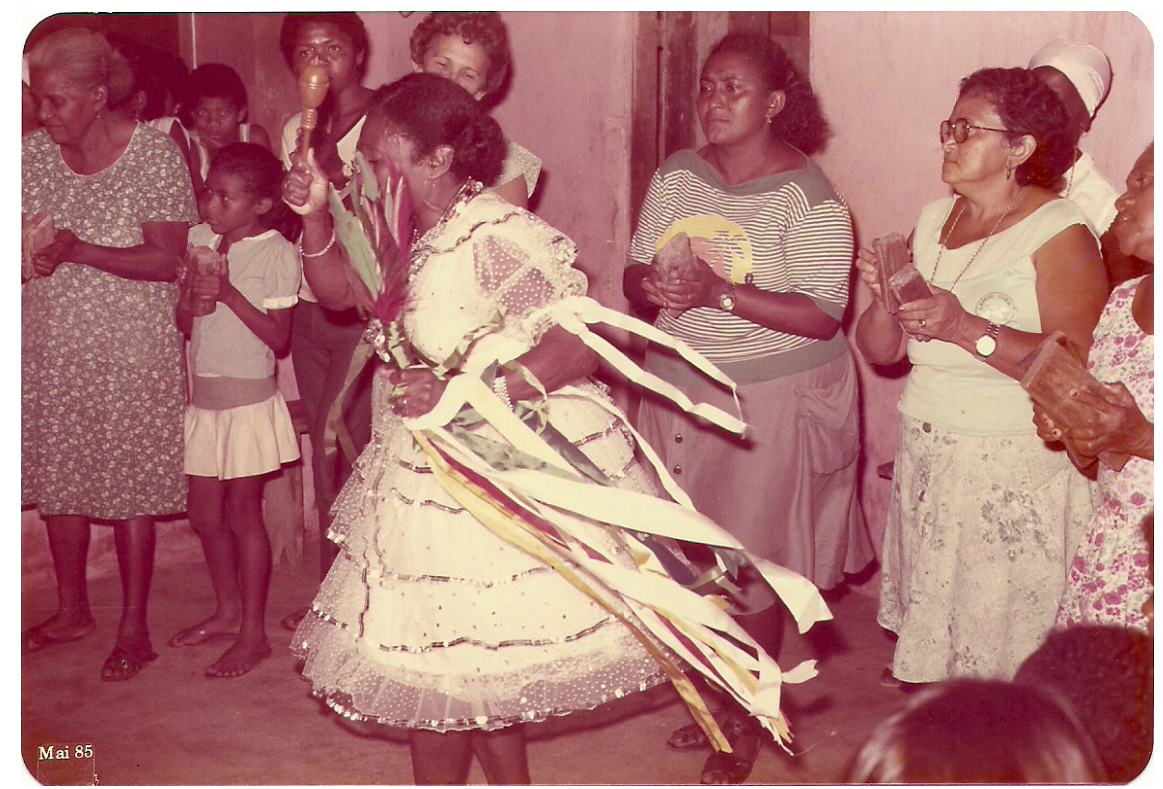

Figura 3: Cura no Terreiro Fé em Deus - Mãe Elzita - São Luís, 05/1985. Foto de Mundicarmo Ferretti.

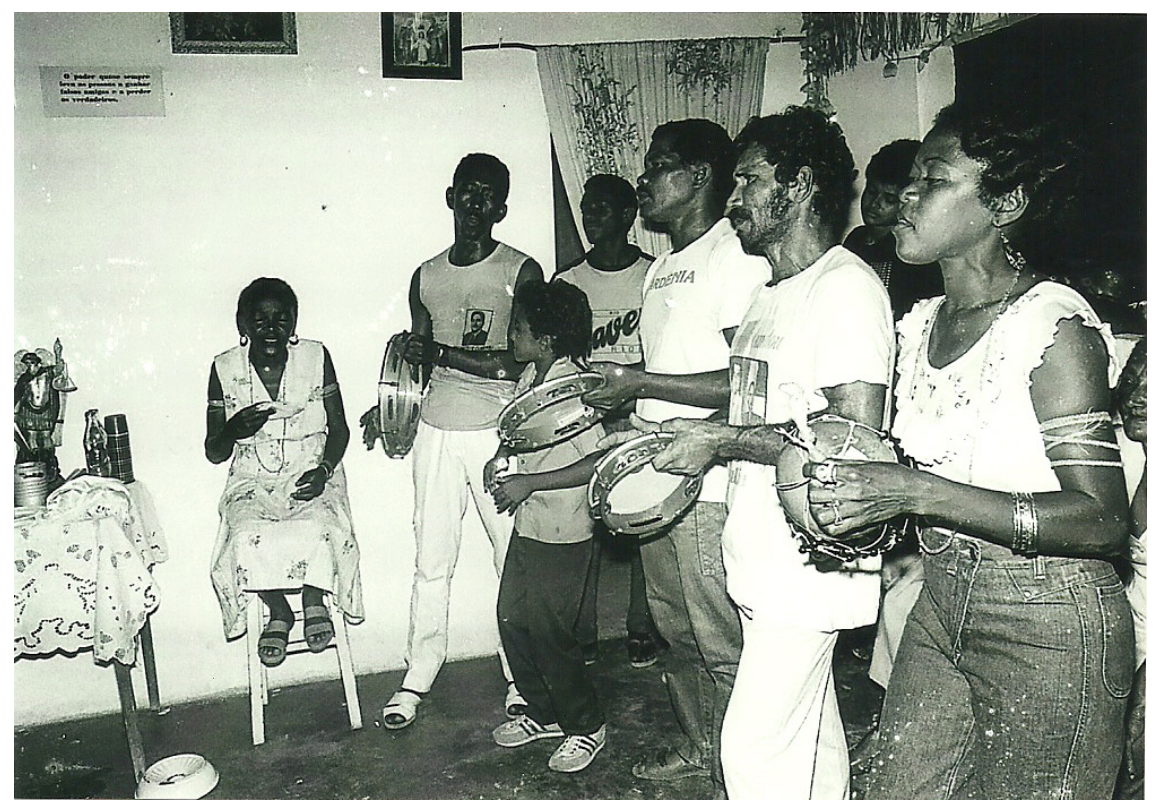

Figura 4: Brinquedo de Cura na Casa Fanti-Ashanti-Pai Euclides - São Luís, 11/1986. Foto de Raimundo Nonato Guterres. Fonte: FERRETTI, op. cit., 2011. Disponível em www.museuafro.ufma.br 


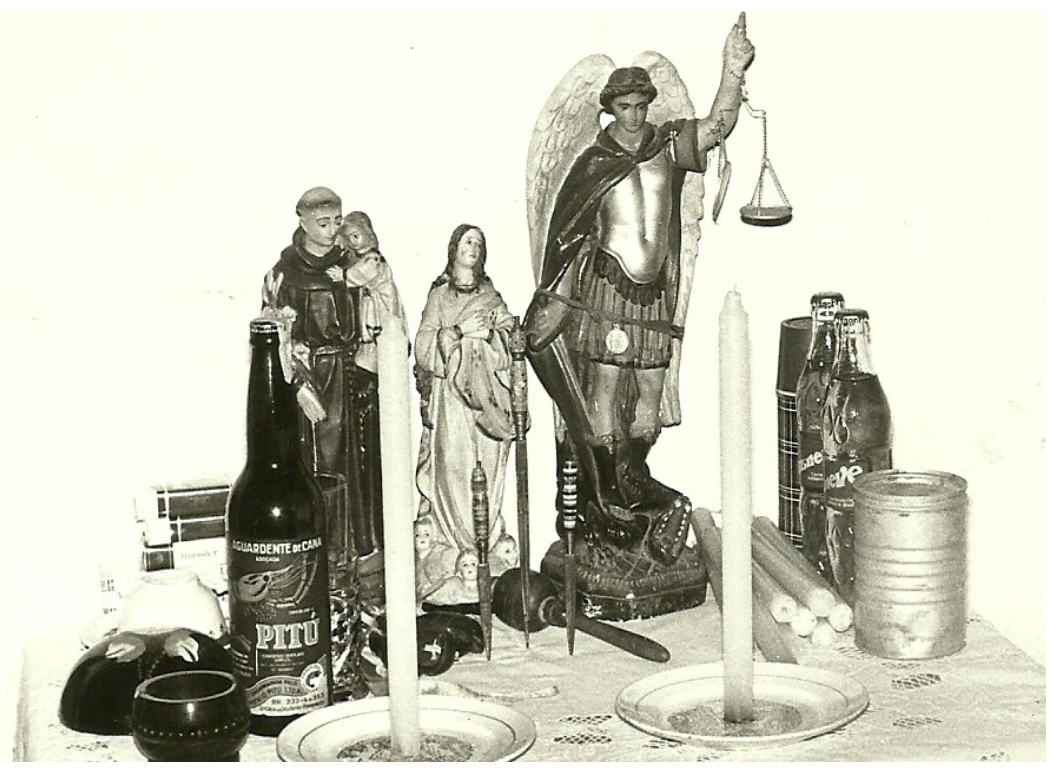

Figura 5: Mesa de Cura na Casa Fanti-Ashanti - São Luís-MA, 11/1986. Foto de Raimundo Nonato Guterres. Fonte: FERRETTI, Mundicarmo. Tambor de Mina, Cura e Baião na Casa Fanti-Ashanti/MA. (disponível em www.museuafro.ufma.br). 
